\title{
Administración pública y populismo en Venezuela
}

\author{
Haydée Ochoa Henríquez* \\ Mirtha López Valladares** \\ Isabel Rodríguez Colmenares ${ }^{* \star *}$
}

\section{Resumen}

El objetivo de este trabajo es estudiar los rasgos generales de la Administración Pública venezolana durante el período democrático. Se plantea la hipótesis que la Administración Pública venezolana se ha caracterizado por prácticas populistas que constituyeron una necesidad de profundización de la economla por sustitución de importaciones y de implantación de la democracia. A partir de esta hipótesis se realiza una exploración a las siguientes variables: sujetos y procesos de decisión, grado de regulación y control, tamaño organizativo, administración del personal y planificación. Los resultados demuestran la presencia de prácticas populistas que tienden a modificarse a raíz de la promoción por parte del Estado de un nuevo modelo económico.

Palabras claves: Administración Pública, Populismo, Economía, Democracia, Venezuela.

Recibido: 27-05-95 . Aceptado: 19-06-96

- Dra. en Estudios del Desarrollo. Investigadora del Centro de Estudios de la Empresa de la Facultad de Ciencias Económicas y Sociales (FCES) de La Universidad del Zulia (LUZ). E.Mail: hochoa dino.conicit.ve. Autor para la correspondencia.

** Maestría en Gerencia Pública. Becaria de Investigación del Centro de Estudios de la Empresa de la FCES de LUZ.

**"Magister en Ciencias Políticas. Investigadora del Centro de Estudios Sociológicos y Antropologlcos de la FCES de LUZ. 


\section{Public administration and populism in Venezuela}

\section{Abstract}

The objective of this article is to study general aspects of Venezuelan Public Administration during the democratic period. The authors use the hipothesis that the Venezuelan Public Administration has been characterized by populist practices needed to give depth to the economy for import substitution and also to implement democracy. From this hypothesis there are explorations of these variables: subjets and decision making processes, degrees of regulation adn control, organization magnitude, personnel management and planning. Results shaw the presence of populist practices whiche tend to be modified though the prometiens by the State of a new economic model.

Key words: Public Administration, Populism, Economy, Democracy, Venezuela.

\section{Introducción}

Nos proponemos en este trabajo explorar los rasgos generales que caracterizan a la administración pública venezolana desde los orígenes de la democracia en 1958.

Sostenemos que desde los inicios de la democracia, los procesos en base a los cuales se formulan y ponen en acción las políticas en el poder ejecutivo, lo que denominamos administración pública, so han orientado con criterios populistas $y$ clientelares, producto de la necesidad de implantar la naciente democracia y de contribuir al crecimiento de los partidos y muy especialmente, de profundizar la economía por sustitución de importaciones.

Observamos que a la polftica de promoción del modelo de sustitución de importaciones le correspondió el estilo de administración pública denominado burocrático-populista por algunos autores (De la Cruz, 1986). Este modelo está siendo desplazado desde mediados de la década del 70 en las instituciones públicas vinculadas a la economía de mercado por un estilo que denominamos tecnocrático. El desplazamiento es más evidente desde fines de los años 80, cuando el Estado a la vez que promueve globalmente la economía de mercado, realiza cambios en su administración pública y reformas tendentes a la tecnocratización, que compiten con las prácticas populistas.

La relación entre Administración Pública y Economfa se ha venido planteado téricamente desde fines de los años setenta en el marco de un paradigma alternativo de explicación del aparato público que intenta trascender el nivel descriptivo que ha predominado en el estudio del funcionamiento del aparato estatal. Estas tesis están tomando fuerza en los úllimos años frente a los cambios ocurridos en el aparato administrativo simultáneamente con los cambios en la economia y en la política estatal. 


\section{El contexto de la administraclón burocrátlco-popullsta}

La calificación de burocrático-populista al modelo administrativo público iniciado con la democracia se debe a que se impone una concepción de la conducción del aparato público, basada en la búsqueda de colaboración de clases, a través del gasto público para el logro de los objetivos, de alll que para algunos autores el populismo se asocia a la renta petrolera (Romero, 1987), aunque en definitiva no es la renta petrolera, sino el uso que a ésta se le ha dado, lo que ha permitido el mantenimiento de este estilo de dirección pública por tan largo tiempo.

Brito Figueroa expresa, que a pesar de la imprecisión del término populismo en las diferentes tesis, dos rasgos unen la diversidad: politicamente todos "buscan el reacomodo de las relaciones de clases o su colaboración pero no la desaparición de las mismas" y, culturalmente, centran el mensaje en la tradición popular (Brito, 1988: 15). Efectivamente, la colaboración de clases con base en el gasto público, es la característica que la mayoría de los autores le asignan a la política populista y es a nuestro juicio, siguiendo las tesis de O'Connor sobre las funciones del Estado, el principal instrumento de legitimación, del cual los grandes beneficiados son los empresarios.

La adopción de este tipo de instrumento de legitimación está vinculada al proyecto político-económico, pero especlalmente al económico impulsado desde la década de los cuarenta y a las condiciones socio-políticas para su profundiza- ción a partir de 1958 con la caída del régimen militar. Tal como dice Luis Gómez:

\begin{abstract}
"El orden politico democrático ha estado asociado a un modelo de desarrollo económico que ya venía desplegándo. se casi sin interrupciones desde la década de los cuarenta. El mismo otorga al Estado un papel de coordlnador y estimulador de los actores económicos y sociales, utilizando sus recursos para absorber los costos y errores de dichos actores". (Gómez, 1995: 107)
\end{abstract}

La industrialización para el consumo interno, es como señalan diversos autores "el centro dinámico alrededor del cual va a girar lo fundamental de la estrategia económica de 1958 en adelanten (López et al, 1989: 37).

Cuando se produce el derrocamiento del gobiemo militar en 1958, el Estado venezolano debe atender dos cuestiones fundamentales: 1) La promoción y estímulo de la economía por sustitución de importaciones y 2) Las demandas sociales reprimidas que estaban directa 0 indirectamente relacionadas con el modelo económico. Sobre la base de estos dos ejes con grandes requerimientos de gasto público, se inicia el experimento democrático.

El estímulo estatal al sector privado para la industrialización se habla iniciado formalmente desde los años treinta con la creación del Banco Industrial de Venezuela, pero más claramente en los cuarenta con la constitución de la Corporación Venezolana de Fomento, sin embar. go en la práctica hasta el derrocamiento 
de la dictadura dicho apoyo era incipiente, el mayor porcentaje de créditos $(75 \%)$, correspondía al sector agropecuario.

Con el derrocamiento de la dictadura militar los sectores económicos reclamaron un mayor apoyo del Estado al proceso de industrialización, lo cual se ve favorecido según Purroy por: 1) los síntomas de agotamiento de la dinámica de expansión simple, 2) consciencia de la dependencia estructural de la economía interna a raíz de las oscilaciones de la producción petrolera en 1958 y 1959 y por último:

...la confluencia de intereses entre sectores de la burguesía, que velan peligrar el proceso de acumulación de capital, la dirigencia de los partidos políticos, algunos de ellos con clerto tinte populista que necesitaba legitimación económica y las crecientes reivindicaciones populares en pro del empleo y acceso a niveles elementales de consumo. (Purroy, 1982: 185)

En este contexto, el Estado venezolano no tiene otra alternativa que prestar apoyo directo al sector privado para promover activamente la industrialización por sustitución de importaciones, pero de modo "más coherente y continuada". (Purroy, 1982: 219)

Paralelamente, como parte del proyecto democrático que sustentó la caida del régimen, el Estado tuvo que dar respuesta a las demandas de satisfacción de necesidades sociales. En tal sentido, incrementa el gasto social a través de una considerable ampliación de la cobertura gratuita de asistencia en los campos de la salud y la educación, entre otros, y el otorgamiento de subsidios a la población en algunas áreas tales como la de vivienda y servicios básicos.

El gasto social es un medio importante en la búsqueda de consolidación de la naciente democracia y se constituye en un significativo instrumento de legitimación de Estado; sin embargo, compartimos la tesis que el gasto social es, fundamentalmente, un requerimiento del modelo económico para asegurar el consumo interno, por un lado, el gasto social contribuye a la reproducción de la fuerza de trabajo y, por otro lado, es una vía para incrementar la demanda (Barrios, 1983), cuestión necesaria debido a la estrechez del mercado.

A los requerimientos populistas del modelo económico y de la estrategia para impulsar la democracia, se suma el temor a la extensión del socialismo en América Latina a ralz de la revolución cubana, lo cual movilizo, a las organizaciones internacionales (CEPAL, BID y OEA) a promover la colaboración de clases para el progreso en el marco de relaciones capitalis. tas de producción y a los gobiernos latinoamericanos a insertarse en la politica de corte populista, universalista y proveedora de servicios para la población.

La colaboración de clases con base en el gasto público, toma expresión, tanto en el contenido de la polftica como en los procesos de formulación y ejecución, en los que estamos interesados en detenernos. Si en el estilo weberiano el principio fundamental de dirección es el cumplimiento de la ley, para el modelo que en este momento nos preocupa, el cumplimiento de la ley cuenta muy poco, lo 
importante es lograr la participación "armónica" de los distintos sectores en el proyecto económico y político, siendo la disponibilidad de recursos fiscales el factor favorable al despliegue de este modelo.

La implantación del populismo tuvo como base estas condiciones objetivas, no se trata de una imposición producto simplemente de la voluntad de los líderes del momento como sugiere Aníbal Romero, para quien era posible tomar otro rumbo "si el liderazgo politico nacional hubiese rechazado la tentación populista y los mitos estatistas de nuestro tiempo, adoptando... una ideología económica favorable a los mecanismos de mercado, a la competencia y la iniciativa de los individuos..." (Romero, 1987: 34).

\section{Los princlpales sujetos de decisión: hombres de partido y empresarlos}

Los principales sujetos de decisión en la administración pública burocráticopopulista han sido hombres de los partidos políticos que se encuentran en el poder y sectores dominantes de la burguesla. En otras palabras, políticos y empresarios son los sujetos que han motorizado las prácticas administrativas burocrático-populistas, desde las instancias decisorias del aparato público. Los empresarios se ubicaron fundamentalmente en Ministerios claves para la economía. Políticos y empresarios dirigen tal como dice Juan Carlos Rey, con "unos pocos grupos organizados (grupos de presión institucionales y asociacionales)" (Rey, 1991: 544), entre los que el autor identifica a los empresarios de la Federación Venezolana de Cámaras y Asociaciones de Comercio y Producción (Fedecámaras); a los trabajadores por intermedio de la Central de Trabajadores de Venezuela (CTV) y a las Fuerzas Armadas a través del Alto Mando Militar.

La ubicación de los técnicos en instancias de decisión ha sido, hasta mediados de los años setenta, una excepción; porque incluso en organismos creados para la tecnificación de la administración pública, tales como la Oficina de Coordinación y Planificación (CORDIPLAN), la cúpula era ocupada por técnicos vinculados discretamente al partido de gobierno.

La inserción de los partidos políticos se consagró en el llamado pacto de Punto Fijo ${ }^{1}$. La mediación de los partidos fue posible en tanto garantizaba no sólo el proyecto democrático, sino también la continuidad y profundización del modelo económico, concretamente protección a la oferta y estímulo al crecimiento de la demanda, cuestiones fundamentales para la economía por sustitución de im. portaciones. Los partidos se ubicaron en los niveles más altos del aparato público en el proceso de toma de decisiones, con lo cual se irradió su presencia a lo largo y ancho del aparato administrativo, para ello la selección del personal directivo de distintos niveles (Gobernadores, Minis-

1 Asi tue llamado el acuerdo entre los partidos Acción Democrática (AD), COPEl y Unión Republicana Democrática (URD), para la defensa de la democracia excluyendo al partido Comunista debido a incompatibilidad de las propuestas programáticas. 
tros, Presidentes de Empresas Públicas, directores y gerentes de distintos niveles) se realiza de las filas del Partido Polftico que se encuentra gobernando; lo cual es posible legalmente dada la calificación de cargos de confianza que se da en la Ley de Carrera Administrativa a los puestos de dirección.

Los organismos de presión intervinieron a través de otros mecanismos: "consejos consultivos ad hoc para proyectos o leyes especíticos; comites asesores a nivel de burocracia; representación de intereses privados en institutos autónomos, entes descentralizados y empresas del Estados; fondos de administración de subsidios estatales, etc." (Rey, 1991: 555). La CTV se asegura desde 1966 la participación permanente de uno de sus directivos en los niveles de decisión de los entes descentralizados, a través de la Ley de Representación de los Trabajadores en los Institutos Autónomos, Empresas y Organismos de Desarrollo del Estado. Dada la subordinación de ésta a la politica de Acción Democrática, este partido garantiza con dicha ley un mínimo de intervención en el proceso de decisiones al salir del poder.

La incorporación de los grupos de presión, especialmente en órganos responsables del diseño de la política económica, es para Rey una forma de dejar un conjunto de decisiones socio-económicas al margen del control y del debate democrático; pero, hay que destacar que los partidos políticos conjuntamente con los empresarios son en este modelo los principales sujetos participantes en la formulación de políticas económicas, por un lado, porque dirigen los órganos respon- sables de definir la politica (Ministerios) y, por otro lado porque algunos organismos de presión están ligados a los partidos, inicialmente la CTV, pero más adelante incluso las Fuerzas Armadas fueron penetradas por los partidos, lo cual se evidencia en los ascensos militares y la presión que se establece en tomo a ello.

De acuerdo a esta estructura de decisiones, el poder se funda para algunos autores "en un complejo juego de fuerzas entre intereses y corporaciones privadas, organizaciones burocráticas, gobiernos locales, partidos políticos, sindicatos, pariamento y gobiemo central" (Oszlak, 1984: 29), sin embargo, en definitiva los grandes beneficiarios, son los sectores económicos y los partidos politicos. Nuestra tesis es que más allá de la inserción directa de esos grupos de presión en el aparato estatal, los partidos políticos y empresarios, como principales sujetos de decisión, estaban comprometidos con promover activamente el modelo de sustitución de importaciones, el cual constitula la única opción económica con la democracia burguesa con liderazgo de los partidos políticos.

En palabras de Rey, desde "1958 ha habido un acuerdo básico entre los principales actores politicos y sociales... sobre el papel central que el Estado debe desempeñar en el proceso de desarrollo, en sus dos aspectos de crecimiento $y$ distribución..." (Rey, 1991: 545), de modo que los partidos como principales mediadores entre el Estado y la Sociedad deben impulsar el modelo de sustitución de importaciones y el bienestar social, necesario para la legitimación de la democracia.

Es necesario añadir, que los parti- 
dos políticos buscaron además su propio crecimiento, hecho que $s \theta$ evidencia en el establecimiento de una práctica administrativa en la cual los propósitos económicos, politicos y sociales del Estado $s e$ vieron mediatizados por prácticas clientelares, es decir se subordinan tales propósitos a intereses partidistas y personales, de este modo "se pasa de la lealtad difusa preservada por políticas generales redistributivas a un sistema de incentivos más particulares $\theta$ individualizados" (Borges, 1992: 94), como diría Gómez Buendla, es "la práctica de ofrecer a individuos o a grupos no categoriales, acceso privilegiado a empleos públicos o servicios del Estado, a cambio de apoyo politico particularista" (Gómez, 1984: 91)

\section{Centralización de las decisiones}

La administración pública la constituye el poder ejecutivo en las tres instancias politico-territoriales: Nacional, Estadal y Municipal. Caracteriza a la administración populista la centralización de las decisiones estratégicas y cotidianas en la cúpula de la administración pública nacional, hecho que está cambiando hoy en dla paralelo a la promoción por parte del Es. tado de una economia de mercado.

Por una parte, la Administración Pública Nacional ha asumido funciones propias del Municipio. A pesar de que formaimente este es una unidad política autónoma, que tal como dice Quintín, "se expresa en la elección de sus propias autoridades, en la libre gestión en las materias de su competencia, y en la crea- ción, recaudación e inversión de sus ingresos propios" (Quintin, 1989: 30); la Administración Pública Nacional desde los inicios de la democracia, ha venido asumiendo servicios propios del nivel municipal, con lo cual se debilita el poder local, los ejemplos más claros son el servicio de agua y electricidad.

Por otra parte, los gobiernos estadales han visto reducidas sus competencias, al respecto dice Quintín:

...hasta ahora gran parte de sus potestades están sujetas a limitaciones $\theta$ intervenciones de dicho Poder. Por otra parte, en materia de ingresos propios. la Constitución establece una larga lista de limitaciones a las potestades tributarias de los Estados, lo cual las reducen a la inexistencia. En definitiva, la "autonomia" de los Estados es una autonomía dependiente del Poder Nacional: existe y tiene ámbito e importancia, en tanto el Poder Nacional lo determine. (Quintin, 1989: 23)

La centralización de las decisiones en la Administración Pública Nacional aparte de dificultar la democratización del poder trae consecuencias negativas en la eficiencia, al respecto opina la Comisión Presidencial para la Reforma del Estado (COPRE) que podría pensarse que:

...la centralización indica una organización eficiente, sobre la base de directivas coherentes con estructuras verticales y funcionales, aunque poco democráticas. Pero lo cierto es que el proceso de centralización no muestra la coho- 
rencia de una estructura vertical, sino más bien una concentración de autoridad y atribuciones de alto grado de ineficacia.

Esta forma de funcionamiento genera, paradojicamente una gran dispersión, distorsión de competencias y anarquía. El funcionamiento tiende a ser inoperante y las decisiones y políticas prácticas, el producto de una controntación de disposiciones contradictorias, marchas y contramarchas que terminan produciendo resultados tardíos, muchas veces incoherentes y de difícil seguimiento. (COPRE, 1988: 52)

Esta situación, aunada a los requerimientos de eficiencia estatal planteados por la economía neoliberal son el motor que ha impulsado recientemente la descentralización político-territorial del Estado venezolano, de hecho la COPRE, institución que ha liderizado este proceso, ha señalado que la descentralización es "un poderosísimo impulso para descongestionar al Estado y permitir su eficiencia" (COPRE, 1988: 60).

Adicionalmente a la centralización político-territorial, a lo interno de administración pública nacional también se centraliza el poder en la cúpula de la organización, en gran medida en el Presidente de la República y el Consejo de Ministros.

La llamada administración descentralizada iniciada en 1928 y con un gran crecimiento a partir de 1958, especialmente con la regionalización iniciada a fines de la década de los sesenta, ha sido una forma de atenuar las ineficiencias de la centralización y ceder espacios de poder en el funcionamiento $y$ en algunos niveles de decisión, conservando el poder la cúpula del aparato público donde se decide sobre el sujeto de dirección de la administración descentralizada. De alli que se ha considerado que este es un proceso de descentralización centralizado. Producto de este fenómeno la Administración Pública Nacional se ha dividido en Administración central y descentralizada con un crecimiento vertiginoso de esta última, donde se ha concentrado la actividad empresarial del Estado. (Ochoa, 1995).

La centralización de las decisiones responde a la necesidad del Estado intervencionista, poseedor de cuantiosos recursos, de ejercer control sobre la distribución de los mismos, en palabras de la COPRE: "...hace posible una relación más directa entre los núcleos del ejercicio del poder y los recursos públicos" (COPRE, 1988: 50).

\section{La planificación: Instrumento de legitimación}

En el marco de una importancia significativa asignada a la planificación en América Latina como instrumento de desarrollo, bajo el liderazgo de la CEPAL, desde los inicios de la democracia en 1958, el Estado ha realizado acciones formales para implantar un sistema de planificación. Como parte de las acciones se cré en 1958 la Oficina Central de Coordinación y Planificación (CORDIPLAN). En el decreto de creación de esta oficina quedan plasmadas las bases de un sistema de planificación que debla involucrar a todas las instituciones y niveles de la administración pública. Vincula- 
do al proceso de planificación estaría el Presupuesto-Programa.

Después de nueve planes nacionales y de haber transitado por varias metodologías (normativa y estratégica), el Estado ha gastado cuantiosos recursos, al ampliar su estructura organizativa y su burocracia no sólo a través de Cordiplán, sino de todo el aparato público debido a la creación de unidades de planificación, aunque algunas en definitiva nada tengan que ver con la planificación.

En la práctica la planificación no ha funcionado como soporte de la acción administrativa, la planificación que debla ser orientadora de la dirección pública, anda por un camino y el presupuesto (tradicional al margen de su denominación de presupuesto por programa) sigue vías diferentes a pesar de la creación de los planes operativos en 1976, como intento de vínculo entre la planificación y el presupuesto. Treinta años después de haberse iniciado el proceso de implantación de un sistema de planificación en el aparato estatal, la COPRE, señala lo siguiente: "En términos generales, la planificación en Venezuela ha sido una actividad técnica con participación limitada en los niveles decisorios y normativos de la Administración Pública" (COPRE, 1989: 176).

Efectivamente la planificación en la administración pública a todos los niveles (nacional, sectorial, institucional etc.) no ha constituido fuente para la toma de decisiones, pero sI ha servido para incrementar la burocracia y legitimación del Estado frente a los organismos internacionales que reclaman su uso.

Las razones por las cuales la plani- ficación no ha alimentado el proceso de decisiones son según la COPRE (1989:176):

- La relativa abundancia de recursos del Estado le ha permitido enfrentar sus obligaciones, sin necesidad de afinar la toma de decisiones.

- El sentimiento de transitoriedad en los cargos conduce generalmente a un pragmatismo, frente al cual, la planificación en su forma tradicional no tiene respuestas oportunas.

- La insuficiencia de mecanismos legalmente establecidos, para obligar a la participación y para permitirla en la práctica.

Para otros autores, la planificación en Venezuela ha fracasado por problemas teórico-metodológicos, concretamente por el uso de la planificación normativa, la cual no considera la viabilidad politica, entendida como la posibilidad de contar con consenso mínimo para la eficacia de los planes. Esta la posición de los proponentes de la planificación estratégica.

Coincidimos con Oszlak en cuanto a que "Los planificadores fracasan habitualmente porque pretenden aunque no lo planteen así o no sean conscientes de ello, influir en un juego -la política- que se rige por reglas diferentes. Nada más ajeno a la polftica que las premisas de neutralidad valorativa, racionalidad sustantiva y certidumbre propias de la planificación" (1984: 14).

El proceso de decisiones, especialmente en sistemas democráticos, obedece a una dinámica politica compleja, en la 
cual entran en juego los intereses de los sectores dominantes, las presiones de diversos actores, resistencias burocráticas y finalmente condiciones objetivas que obligan a decisiones que muchas veces nada tienen que ver con lo planificado o con la voluntad de quienes formalmente dirigen el aparato estatal.

Entonces, por qué se gastan cuantiosos recursos en la planificación?. Oszlak dice la respecto, siguiendo a Wildavky:

...no persiste tanto por lo que consigue como por lo que simboliza: racionalidad. Los estuerzos de los planificadores presuntamente resultan en propuestas de política eficientes, sistemáticas, coordinadas y consistentes. Términos como éstos revelan la superioridad de la planificación pues, al igual que la "mano invisible" de la economía clásica, proporciona un mecanismo de control social que permite regular óptimamente la asignación de valores en la sociedad. Su virtud reside entonces en que corporiza criterios universales de elección racional. (Oszlak, 1984: 14).

En esta misma línea de pensamiento se ubican otros autores, para quienes el Estado venezolano tha mantenido en sus tres últimas décadas un Sistema Nacional de Planificación donde la actividad de planificación ha actuado como una ideología legitimadora..." (Giordani et al, 1992: 22)

Cientamente la planificación ha cumplido un rol ideológico tanto por el discurso a favor de lo social, (COPRE 1988: 65), como por su connotación de eficiencia. Pero es necesario precisar, que el mantenimiento de la planificación ha requerido de cuantiosos recursos, es decir de incremento del gasto público y éste es necesario para el modelo económico y para la democracia, de esta manera la planificación ha logrado mantenerse como instrumento ideológico.

Con la promoción estatal de una economía de mercado, plasmada en el VIII Plan de la Nación, para algunos autores la planificación cambia la presentación con fraseologfa neoliberal, pero el plan sigue siendo un instrumento de legitimación (Giordani of al, 1992: 96), sin embargo, la profundización del aparato estatal a favor de la función de acumulación, a ralz de la economía de mercado, hace suponer que habrán cambios en el papel de la planificación, en tal sentido, es significativo que entre las proposiciones actuales de la COPRE (1994: 145), respecto a la reforma estructural de la administración pública, se encuentra la adscripción del Sistema de Planificación y Presupuesto a un propuesto Ministerio de Desarrollo Económico, aunque se plantea que no tendría un sesgo económico, es diffcil creer que en tiempos de profunda hegemonía de la dimensión económica, el Ministerio, en cuestión, no priorice lo económico.

\section{Regulación excesiva y débll control}

Desde los inicios de la democracia la solución de gran número de problemas ha pasado por la creación de instrumentos legales: leyes, reglamentos, decretos etc. cuyo contenido responde fundamen- 
talmente a las dos vertientes sobre las cuales se orienta la actividad estatal desde 1958: la promoción de una economia para el consumo interno y la implantación de la democracia.

Con frecuencia este cuerpo normativo es contradictorio, "en muchas circunstancias, El Congreso de la República aprueba una legislación sin tomar en cuenta el antagonismo y la contrariedad que puede tener sobre otra existente, tal como ha sucedido con la Ley Orgánica de Descentralización, delimitación y transforencia del Poder Público y con la Ley Orgánica del Sistema Nacional de Salud. Asimismo al entrar en funciones un nuevo gobierno, éste autoriza disposiciones no compatibles con las vigentes y a veces ni siquiera las deroga" (Quiroz, 1992: 120).

Con algunas excepciones, en el cuerpo normativo se plasman no sólo las políticas más generales, sino también estrategias, estructuras organizativas $y$, en general, el modelo administrativo que ha de utilizarse formalmente para poner en marcha las politicas, para decirlo en palabras de Garcia Pelayo al referirse a la racionalidad burocrático jurídica:

La división de tareas se configura como distribución de 'compatencias', es decir de círculos jurídicos que delimitan ámbltos de actuación, deberes y atribuclo. nes; la asignación de funciones instituclonales y personales se expresa en el 'cargo', o sea en una posición dentro del sistema jerárquico y definida por la ley; todo procedimiento y toda decisión han de tener fundamento legal... (Garcla, 1974: 28)
Esta rigidez formal da poca cabida a la discrecionalidad, debido al carácter estático del derecho, "...el derecho por lo mismo que trata de asegurar una regulación cierta y constante de las cosas, tiende a ser estático, a fijar las relaciones de una vez por todas o para grandes periodos de tiempo..." (García, 1974: 29).

A juicio de algunos autores, la necesidad de reducir la discrecionalidad es la razón de la profusión y compiejidad de las normas. Al respecto dice Oszlak:

La profusión de normas y complęlldad de procedimientos resultante, produce otras consecuencias. En conjunto, normas y procedimientos permilen reducir al mínimo el ámbito de responsabilidad de cada rol a fin de evitar al máximo los posibles riesgos de la decisión. La norma es invocada para diluir estos riesgos y mantener las formalidades. (Oszlak, 1984: 31)

Pero si bien es cierto, que las caracteristicas de las normas reducen la discrecionalidad en las decisiones; la maraña legal incrementa la capacidad de decisión, porque las contradicciones deben resolverse y alli entra en juego la posibilidad de favorecer a uno $u$ otro sector, de modo que en definitiva es un sistema legal que por su naturaleza y proceso de aplicación beneficia a los sectores dominantes.

La creación de normas es además, una forma de filtrar demandas y diseñar soluciones a problemas, por parte de algunos sectores sociales, en el marco de una cultura que ve en la Ley la solución 
Administración Pública y Populismo

Haydee Ochoa, Mirtha Lopez, Isabel Rodriguez

de los problemas, aunque en la práctica el esquema normativo se constituya en letra muerta, esto se demuestra con el escaso cumplimiento de muchas leyes, basta tener presente que existiendo una Ley de Salvaguarda del Patrimonio Públi$\mathrm{co}$, tenemos una corrupción sin precedentes en la historia del país.

La profusión de la ley es también una necesidad del crecimiento burocráti$\mathrm{co}$, detrás de cada instrumento legal por lo general se encuentran algunos sectores sociales esperando para incorporarse al ejercicio del poder en determinados espacios de la sociedad.

Debido a la excesiva regulación, una de las críticas más resaltantes que se hace a la administración pública burocrático-populista es que tiene exceso de control.

Pero contradictoriamente, en la práctica los controles son débiles, tanto los controles a lo interno del aparato público como los controles a la sociedad civil, de modo que muy lejos está el modelo burocrático populista de un estilo administrativo weberiano.

Si entendemos por control el proce. so de seguimiento de políticas, objetivos y metas, plasmados en leyes, reglamentos, decretos, planes, programas, proyectos etc., tenemos que concluir que hay ausencia de control $y$, en el mejor de los casos, un débil control. En este sentido estamos en desacuerdo con Prats i Catalá, para quien en la administración del Estado de bienestar "la legitimidad legal de la acción administrativa se impuso como legitima, única y suficiente" (Prats, 1992: 61).

La administración pública venezo. lana ha diseñado procedimientos para operacionalizar el cumplimiento del cuerpo normativo, a través de los cuales se debe exigir cumplimiento a la sociedad civil y al propio Estado. Formalmente estos procedimientos constituyen un sistema de entrabamiento más que de control, con las caracteristicas que muchos criticos le han asignado al modelo weberiano: rigidez, demora, mecanicismo y frialdad humana entre otras (Kliksberg, 1973: 152).

Este sistema formal de control, escasamente se cumple en la práctica, el burócrata, que nada tiene que ver con la burocracia weberiana, responde más a los intereses de los sectores dominantes, del partido y de sus amigos que al cumplimiento de la ley. Como ejemplo de esta ausencia de control, basta tener presente la reciente crisis de las instituciones financieras del pals, la cual estuvo favorecida por un débil control por parte de las instancias del Estado responsables de tal función.

Es común el uso de prácticas clientelares para dar cumplimiento a la regulación y a los procedimientos establecidos. Estas prácticas se iniciaron teniendo como contraprestación el voto para el partido 0 el apoyo que interviene en la solución del problema, pero posteriormente la contrapartida ha sido la comisión, creándose un sistema de corrupción que presiona a los ciudadanos a involucrase en él, en tanto, en muchos casos, es la única forma de encontrar la prestación del servicio.

De esta forma, el cumplimiento de los derechos de los ciudadanos se subordina a intereses de los partidos e intere- 
ses personales de quienes intervienen en las decisiones y acciones del aparato público.

Como parte de las actuales demandas de reforma ocupan un lugar importante la desregulación y el sistema de control, el nuevo modelo económico necesita garantía de respuestas ágiles y de cumplimiento legal y, de hecho, se están dando avances en este sentido, ello nos revela que los cambios económicos constituyen el motor de las reformas administrativas del aparato público.

\section{Crecimiento burocrático}

El crecimiento burocrático (instituciones y empleo) constituye el rasgo comúnmente identificado en el modelo. Roberto Esteso nos dice que una de las características de la burocracia propia del patrón de autonomfa capitalista nacional es el crecimiento del empleo. (Esteso, 1986: 14)

Ese crecimiento tuvo lugar a través de la conformación de un amplio aparato público y la creación de un gran número de cargos. En general, frente a nuevos objetivos la respuesta inmediata es el crecimiento burocrático. Globalmente este crecimiento no es exagerado, las cifras revelan que Venezuela está muy por debajo de muchos países en tamaño burocrático (Quintín, 1996), el problema es la distribución, exagerado número de instituciones y cargos en algunas áreas $y$ reducido en otras, lo cual es producto del uso de criterios de crecimiento para dar respuesta a demandas de diversos sectores sociales.

Si bien la estructura ministerial se mantuvo hasta 1976 (13 ministerios), se produjo la expansión interna de los ministerios, tanto a nivel de la administración central como de la descentralizada. Se crearon además las oficinas adscritas a la Presidencia de la República: personal, planificación, presupuesto e información.

A partir de 1974 la disponibilidad de cuantiosos recursos fiscales por parte del Estado, derivados del boom petrolero, motivaron un crecimiento descomunal del aparato público, intensificado en 1976 con la ampliación de la estructura ministerial a través de la Ley Orgánica de la Administración Central al elevarse de 13 a 17 los ministerios.

Las instituciones creadas conformaron un amplio aparato público estrechamente vinculado a la economía; se destaca la constitución de numerosas empresas públicas ubicadas en diversas ramas de la economía, para dar respuesta a las demandas de los sectores económicos, especialmente crediticias $\theta$ igualmente se conformó un considerable aparato público de tipo social que debla dar respuesta a las presiones en tomo a vivienda, salud, seguridad social etc., y que a su vez contribula a incrementar la demandas, cuestión necesaria para la producción dirigida al consumo interno.

Es importante señalar, que a ralz del boom petrolero comienza a adoptarse de modo sistemático un estilo de administración pública diferente al populista, en las empresas nacionalizadas (petróleo, hierro y electricidad), en nuevas empresas del Estado y en viejas empresas públicas redimensionadas para vincularlas al mercado internacional (petroquímica y carbón). Ese modelo lo hemos denomina- 
do tecnocrático, su criterio básico de dirección es el crecimiento económico y el logro de ciertos niveles de eficiencia en las instituciones públicas. De tal manera que, el crecimiento burocrático a partir de 1974 se distribuye entre criterios populistas y tecnocráticos; $y$, si bien, el espacio institucional populista pierde importancia relativa, no deja de ser importante debido a su estrecha relación con las instituciones ligadas a la legitimación de la democracia y al modelo por sustitución de importaciones, el cual recibió cuantiosos recursos para su dinamismo.

La creación de numerosas instituciones trae consigo el crecimiento del empleo, pero además éste se vio favorecido por la incorporación de personal para dar respuesta a las demandas clientelares de los partidos politicos.

El crecimiento burocrático se caracterizó por la constitución de organizaciones con similares propósitos y funciones, aisladas unas de otras con bastante frecuencia, hasta el punto que para algunos autores el gran problema del Estado es la falta de coordinación. (Combellas, 1996). Esto es considerado un problema técnico, es decir de incapacidad administrativa, ésta es la concepción que han sustentado los proyectos de reforma organizativa de la administración pública, los cuales en definitiva no han logrado atacar estos problemas.

En el fondo este "desorden" y duplicación de funciones es una respuesta a la necesidad de atender demandas similares de diversos sectores, en su lucha por obtener recursos del Estado. Sobre el carácter político de esta situación dice Oszlak: "las duplicaciones y superposiciones deben interpretarse a la luz de las exigencias y restricciones de un juego polftico que altera la dinámica de las relaciones intra-burocráticas formales, pero que es parte constitutiva y hace a la esencia del régimen que contribuye a caracterizar" (Oszlak, 1984: 32).

El crecimiento de cargos a que da lugar la expansión institucional, da respuesta a las demandas de empleo, lo que, a su vez, favorece el incremento de la demanda de bienes y servicios producidos por el aparato industrial. Esta es la manera fundamental a través de la cual los partidos políticos han podido responder a las cuantiosas demandas de trabajo de sus miembros.

\section{Administración de personal cllentelar}

La Comisión de Administración Pública (CAP) creada en 1958 por recomendación de Herbert Henmerich, funcionario de las Naciones Unidas, se planted la administración de personal como linea de reforma desde sus inicios, como consecuencia de ésto se aprobó en 1960 el Reglamento de Administración de Personal para los servidores del Gobiemo $\mathrm{Na}$ cional. La CAP llega incluso a concentrar la atención en esta línea de trabajo, producto de lo cual 1) Se promulgó en 1970 la Ley de Carrera Administrativa ${ }^{2}$ que contempla los siguientes subsistemas: Autónomos, excluyendo algunos segmentos de estos espacios de la administración pública. 
reclutamiento y selección; clasificación y remuneración; calificación de servicios; adiestramiento, registro y control 2) $\mathrm{Se}$ creó la Oficina Central de Personal como órgano rector de la politica de personal del Estado.

Se buscaba con estas propuestas modernizar la administración pública teniendo como modelo las propuestas weberianas que de algún modo han funcionado en los paises desarrollados, en tal sentido:

El reclutamiento se supone que se hace en base a la preparación de los individuos, modida por exémenes objettios y no por criterlos de otra indole, como pueden ser amistad, familiares, partidos politicos etc. La ubicación, traslado y promoción debe hacerse en base a crterlos tócnicos, en vez de criterios como los recién mencionados. Los funcionarios actuan como protesionales asalariados, se considera su trabajo como una carrera. De alli la idea de que la carrera administrativa es una profesión que está por encima de la profesión o especlalización que pueda tener cada persona.(Silva, 1982: 87)

En la práctica, los subsistemas de administración de personal definidos on la Ley de Carrera Administrativa y otros que de hecho existen, presentan características muy particulares on el modelo burocrático-populista que lo distinguen claramente de otros estilos de dirección, asi como del cuerpo normativo existente.

Formalmente el subsistema de Reclutamiento y Selección tiene como finalidad la escogencia de los mejores, en tal sentido reza el artículo 35 de la Ley de Carrera Administrativa:

La selección para el Ingreso a la carrera administrativa se efectuará mediante concursos a los cuales se dará la mayor publicidad posible. Tales concursos estarăn abiertos a toda persona que reúna los requisitos previstos en el articulo anterior y los que se establezcan en las especificaciones del cargo correspondiente, sin discriminaciones de ninguna Indole. La referida selección se efectuará mediante la evaluación de los aspectos que se relacionen directamente con el correspondiente desempeño de los cargos.

Muy lejos está la práctica de reclutamiento y selección de esta normativa. El reclutamiento lo realizan en gran medida los partidos políticos con posibilidades de poder, los aspirantes a ingresar a la administración pública acuden a los partidos a solicitar empleo en la administración pública, en consecuencia el proceso de reclutamiento es una fase de la administración de personal que tiene lugar excepcionalmente. A juicio de la Comisión de Reforma y Estudio Fiscal ${ }^{3}$, las razones por las cuales la Administración Pública acogida por el Presidente Luis Herrera Campins y creada según Decreto No. 550 del 2-3-80, con el propóslto de estudiar la problemática físcal venezolana, como parte de lo cual se estudiaron algunos sistemas administrativos, entre ellos el de administración de personal. 
minimiza el esfuerzo de reclutamiento son la alta oferta espontánea y respecto a los criterios utilizados en el proceso de reclutamiento ha señalado lo siguiente: "Los criterios utilizados para el reclutamiento están fundados en las recomendaciones de los directores o del resto del personal que trabaja dentro del organismo" (Comisión de Estudio y Reforma Fiscal, 1983: 637).

La selección se realiza de la lista de elegibles que presenta el partido, en algunos instituciones más abiertamente que en otras, pero en esencia este es el mecanismos dominante. Según la Comisión de Estudio y Reforma fiscal, 10 "criterios o medios de selección de personal... actúan como simples formalidades para proceder a ingresar a un personal previamente seleccionado en base a recomendaciones" (Comisión de Estudio y Reforma Fiscal, 1983: 638).

Se han dedicado importantes recursos en la constitución de unidades de reclutamiento y selección a lo interno de las Oficinas de Personal en las distintas instituciones públicas, las cuales en definitiva son tramitadoras de decisiones tomadas con criterios clientelares.

En cuanto a la capacitación, la ley prevé que es una responsabilidad de la OCP conjuntamente con las oficinas de personal, pero a lo interno de éstas ni siquiera ha habido interés en la conformación de unidades organizativas responsables por la organización de la capacitación. En general, este es un problema latinoamericano, al respecto dice Bernardo Kliksberg:

En los organismos públicos de la mayoria de los paises de la región, tales actividades tienen una identidad muy baja on la organización. O no existen unidades de capacitación, o blen se hallan mezcladas con otras divisiones o constituyen oflcinas marginales ubicadas en los últimos casilleros del organigrama, sin acceso a los niveles gerenciales. (Kliksberg, 1989: 31)

En una investigación realizada por la OCP, a inicios de los años 80 , se encuentra que el $40 \%$ de las instituciones encuestadas no disponía de unidad organizativa responsable del adiestramiento (Arapé, 1981: 117), es decir, que constitufa una función inorgánica.

Pero, al margen de esta situación, tenemos que desde los inicios de la democracia, bajo la influencia de la asesorla de las Naciones Unidas, el Estado creó en 1962, el Centro de Adiestramiento y Formación Profesional en el Ministerio de Hacienda 4 y adscrita a la CAP la Escuela Nacional de Administración Pública (ENAP). En ambos centros se hicieron esfuerzos importantes de tecnificación de los funcionarios públicos, hasta mediados de los años 70 , cuando a ralz del boom petrolero se intenta darle una nueva orientación a la ENAP, que termina reduciéndola a su mínima expresión (Ochoa, 1986: 10). 
Estos esfuerzos de oferta de capacitación por parte del Estado a sus funcionarios, tienen lugar al lado de una profunda indiferencia a lo interno de las instituciones públicas respecto a la necesidad de formación del personal, la inexistencia de organicidad relativa a esta función as! lo revela.

La capacitación no constituye una demanda de la dirección del aparato público, en la práctica tienen lugar en medida considerable a partir de solicitudes de los interesados, sin mayor consideración sobre su pertinencia, en este contexto las mayores posibilidades de formación las tienen los funcionarios más cercanos al poder, proceso en el cual la prácticas clientelares entran en juego.

Esta indiferencia hacia la formación del personal público es explicable por la escasa importancia que el modelo administrativo le asigna a la eficiencia como criterio de dirección.

Con el boom petrolero hay mayores posibilidades de capacitación; sin embargo, -con excepción del grupo de empresas tecnocráticas-, el proceso tiene la misma tendencia. De alli que para inicios de los ochenta en la evaluación realizada por la OCP, entre sus conclusiones se tiene:

El valor práctico del adiestramiento tiene una estrecha relación con el grado en que está orientado hacia objetivos realmente prioritarios y perfectamente determinados. En este aspecto, la situación presenta serias insuficiencias: existe todavla una fracción de organismos que no cuentan con objetivos generales establecidos, hay otro sector que los tienen pero sin el adecuado nivel de operatividad, las metodologlas empleadas para fijar objetivos difieren en casi tres cuartas partes de las organizaciones de las que los mismos responsables de adiestramiento consideran las más convenientes para ellas. (Arapé y Kliksberg, 1981: 118),

En el marco de las propuestas de reforma del Estado que se realizan desde mediados de los ochenta, paralelo a presiones por nuevos rumbos en la orientación económica del Estado, se pone especial cuidado en la capacitación como un requerimiento fundamental para transformar el Estado, pero el énfasis se realiza en los niveles gerenciales, la capacitación, es hoy en dia, una función que está cambiando calladamente, sin planes globales, las instituciones están avanzando. En este sentido, sostenemos la hipótesis que su contenido apunta a la tecnocratización del funcionario, al margen de los requerimientos sociales, en todo caso es un tema para discutir en otro trabajo.

Finalmente, en cuanto a la organización del trabajo, es decir, "la forma como se reparten y como se reúnen las tareas y funciones distintas en los puestos o grupos de trabajo" (PRIES, 1993: 59), lo que en administración de personal se denomina clasificación, se conforma en la práctica, en gran medida, producto $d e$ las relaciones clientelares $\theta$ intereses de los grupos en el poder.

La división horizontal del trabajo formalmente está influenciada por las técnicas administrativas modernas, pero la práctica está muy distante de éstas. Si bien es cierto que en toda institución la 
organización formal es diferente a la llamada organización informal, producto esencialmente, de la contradicción de intereses entre la dirección y la burocracia, en la administración burocrático-populista tales diferencias se profundizan debido a la violación del modelo normativo por parte de la propia dirección al asumir prácticas clientelares. Es frecuente el ingreso de personal para realizar tareas que nada tienen que ver con el cargo asignado porque asumen funciones diferentes, o se ubican, en la práctica, en otras instituciones, entre ellas, el partido político. En definitiva, el trabajo se organiza más en función de las necesidades de los funcionarios que de los objetivos formales de la institución.

\section{Concluslones}

Con el advenimiento de la democracia en Venezuela a partir de 1958, se imponen criterios populistas y clientelares en los procesos a través de los cuales se formulan y poneń en ejecución las políticas, es decir en la administración pública.

El estilo administrativo populista ha favorecido el dinamismo del modelo de sustitución de importaciones y la implantación de una democracia de partido, entre otros medios, a través de: La contormación de un cuadro de dirección capaz de generar las políticas públicas comprometidas con ambos proyectos; la centralización del poder necesaria para orientar los recursos fiscales hacia los proyectos en referencia; el crecimiento burocrático para incrementar la demanda que requiere una economía para el consumo interno, asi como, la satisfacción de necesida- des básicas por parte de algunos sectores de la población; la conformación de funcionarios comprometidos con los partidos y con bajo nivel de capacitación para que no puedan constituirse en fuente de presiones para el cambio; el uso aparente de modernos sistemas técnico-administrativos que han servido de instrumento de legitimación frente a organismos internacionales y presiones tecnocráticas y un débil sistema de control que ha permitido a los sectores dominantes evadir la compleja estructura de regulación aplicable en gran medida a quienes no tienen acceso al poder.

Los grandes beneficiarios de este modelo de administración estatal han sido los empresarios y los partidos politicos. La democracia se vio afectada al trenarse su desarrollo, reduciéndose a una democracia electoral cada cinco años para elegir Presidente de la República y Cuenos Legislativos. La acción de los partidos como principales sujetos de dirección pública, estuvo dirigidà a la búsqueda de crecimiento para mantenerse en el poder con adormecimiento de la población, la cual al recibir ciertos beneficios e información manipulada acepta pasivamente las prácticas clientelares que han marginado a gran parte de la población.

De este proceso, resultó un aparato estatal con muy poca eficacia en el cumplimiento de los fines declarados, poco efectivo en la atención de las necesidades básicas de la población y elevados costos, todo lo cual ha contribuido a que estos problemas sean señalados como la causa de la crisis actual del Estado para justificar la reducción de su tamaño, ocul- 
Tecnocracla. Alianza Editorial. Madrid.

Giordani C. Jorge A., Castellano B., Hercilio y López, Jesús (1992). La planiflcaclón venezolana en los noventa. Cendes y Vadell Hermanos Editores. Caracas.

Gómez Buendía, Hernando (1984). "Lo PatoIóglco y lo Democrátlco del Cllentelismo". En: Nueva Socledad No. 74. Caracas.

Gómez Calcaño, Luis (1995). "Crisis de Legltimldad $\theta$ Inestabllidad politica on Venezuela". En: Revista Venezolana de Economfa y clenclas Sociales No. 2-3. Caracas.

Kliksberg, Bernardo (1973). "La Raclonalldad Irracional de la Burocracla". En; Cuestionando en Administración. Paldos. Buenos Aires.

Kliksberg, Bemardo (1989). Gerencla Pública en Tlempos de Incertldumbre. Instituto Nacional de Administración Pública. Madrid.

López Maya, Margarita, Gómez Calcaño Luis y Maingón, Thafs (1989). De Punto Fljo al Pacto Soclal. Desarrollo y Hegemonla on Venezuela (1958-1985). Fondo Editorial Acta Cientifica Venezolana. Caracas.

Malavé Mata, Héctor (1987) Los Extravios del Poder. Universidad Central de Venezue la. Ediciones de la Biblioteca. Caracas.

Ochoa H., Haydée (1986). "Reflexiones sobre la formación del Gerente Públlco como estrategla para la reforma del Estado". Documento. Centro de Estudios de la Empresa. Facultad de Ciencias Económicas y Sociales. Maracaibo. Venezuela.

Ochoa H., Haydée (1995). "La actlvidad empresarial del Eetado venezolano. Auge, contracción y vigencla actual". En Cuestiones Politicas No. 14. Revista del instituto de Estudios Politicos y Derecho Públlco de la Facultad de Clencias Juri- dicas y Politicas de la Universidad del Zulia. Maracaibo. Venezuela.

Oszlak, Oscar (1984). "Polftlcas Públlcas y Regimenes Politicos: Reflexlones a partir de algunas experienclas latino mericanas. Documentos del CLAD. V, I No. 1. Caracas.

Prats i Catalá (1992). "La Modernlzación Admknistrattva en las Democraclas Avanzadas: La Polftica de los 80". En: La Modemización de la Administradón Pública. Dilemas y Desafíos. CLAD. Selección de Documentos Claves, Vol. 9 No. 2. Caracas.

Pries, Ludger (1993). "El reto de la flexiblildad $y$ las relaciones obreropatronales en Móxlco". En: Trabajo industrial on la transictón: experiencias de América Latina y Europa. Editorial Nueva Sodedad. Caracas.

Purroy M., Ignacio (1982). Estado e Industriallzación en Venezuela. Valencla. Venezuela. Vadell Hermanos Editores. Caracas.

Quintín, Antonio (1989). "Amblto Organlzzacional de la Gerencia Públlca". Docur mento de la COPRE. Caracas.

Quintín, Antonio (1996). "Roforma dol Estado en Venezuela. La Modernización Organtzacional". Conterenda dlctada en el Seminario sobre Gerencla Municipal. Maracaibo. 7-2-96.

Quiroz S. Joś6 Rafael (1992). Sector Públlco y Neollberallsmo. Academia Nacional de las Ciencias. Caracas.

Pley, Juan Carlos. (1991). "La Democracla Venezolana y la Crisls del Sistema Popullsta de Conclilación". En: Revista de Estudios Polliticos No. 74. Madrid.

Rornero, Anibal (1987). La Miserla del Popullemo. Ediciones Centauro. Caracas.

Silva Michelena, José Agustín (1982). "La orgenización y el funclonario público: nocesidad de un nuevo modelo". En Revista Venezolana de desarrollo administrativo. Caracas. 
tando las razones reales de la implantación de lo que se ha denominado modelo burocrático populista.

Para Oszlak estos rasgos administrativos son propios de los regímenes democráticos, sin embargo en los últimos años se ha observado que el estilo de dirección que hemos denominado populista ha venido siendo desplazado en los Estados democráticos para dar paso a otro modelo que, a juicio de Oszlak, corresponde a los regímenes autoritarios. Este proceso nos confirma que, si bien la administración pública es producto de la incidencia de múltiples variables, la mayor influencia la tiene la dimensión economica y no la pollitica.

Desde mediados de los años 70 se están produciendo discretamente cambios en las empresas públicas vinculadas al mercado internacional, estos cambios son más claros y ampliados a raíz de la promoción por parte del Estado de una economía de mercado, observamos algunas tendencias en la administración pública que hemos denominado tecnocráticas porque priorizan el crecimiento de la economfa, en cuyo marco los problemas sociales se agudizan, el manto de la eficiencia oculta las razones reales de este "nuevo modelo".

\section{Referencias Bibliográficas}

Arape Morales Alberto y Kliksberg, Bernardo (1981). Dlagnóatlco de la Situación del Adlestramiento en ta Administraclón Públlca Venezolana. Oficina Central de Personal. Caracas.

Barrios, Sonia (1983). "Centrallzación del Poder y Concentración Geográflca. EI
Caso del A.M. de Caracas". Caracas. Documento del CENDES.

Borges, Welkis (1992). "El modelo polftico venezolano: los fundamentos del consenso y la realidad actual". En: Cuestiones Políticas No. 9. Revista del Centro de Estudios Politicos y Administrativos de la Facultad de Derecho de LUZ. Maracaibo. Venezuela.

Brito Figueroa, Luis (1988). La Máscara del Poder. Alfadil Ediciones. Caracas.

Combellas, Aicardo (1996). "La retorma del Estado. Los Camblos Estructurales - Instltuclonales". Conferencia dictada on el Seminario sobre Gerencia Municipal. Maracaibo 7-2-96.

Comisión de Estudio y Reforma Fiscal (1983). Informe Final. Caracas.

Congreso de la República de Venezuela (1975). Ley de Carrera Administratlva. Caracas.

COPRE (1988). La retorma del Estado. Volumen 1. Caracas.

COPRE (1989). La reforma administrativa Volumen 6, Tomo 1. Caracas.

COPAE (1994). Reforma de las Instituciones de Goblemo. Propuestas para la modemización del poder ejecutivo. Volumen 11. Caracas.

De la Cruz, Rafael (1986). "Venezuela en Busca de un Nuevo Pacto Social". Caracas. Documento del CENDES.

De Mattos, Carlos A. (1993). "Descentralizaclón, Particlpación y Democratizaclón: Una Rolaclón Causal?. Trabajo presentado en el I Congreso Iberoamertcano de Ciencla Politica. Santiago de Chile.

Esteso, Roberto L. (1986). "Reflexiones sobre las tendenclas de la Intervenclón y la burocracla estatal". Rlo de Janelro. Ponencla presentada en el XVI Congreso Latinoamericano de Sociología.

Garcla Pelayo, Manuel (1974). Burocracla y 